\title{
A OPERAÇÃO CONDOR E A EMENDA KOCH
}

\section{Waldemar Dalenogare Neto}

A Operação Condor foi uma estrutura repressiva transnacional organizada pelas agências de inteligência de seis países da América do Sul para promover a vigilância e, a partir desta, difundir perseguição, tortura $e$ assassinatos políticos. ${ }^{2}$ Centenas de pessoas foram obrigadas a buscar exílio $e$ outras tantas foram brutalmente assassinadas pela aplicação da Doutrina de Segurança Nacional promovida pelas ditaduras militares de Argentina, Bolívia, Brasil, Chile, Paraguai e Uruguai, que fixaram um claro objetivo de liquidar com o que chamavam de 'subversão marxista'. ${ }^{3}$

Apesar da Operação Condor ter sua organização concebida no começo da década de 1970, durante duas décadas as articulações feitas pelas ditaduras ficaram protegidas em um enorme muro de silêncio e segredo. A publicação de trabalhos como o de Chomsky e Herman ${ }^{4}$ - que denunciava as violações dos direitos humanos dos regimes classificados como 'subfacistas de terceiro mundo' tinham pouca repercussão dentro do meio acadêmico - muito por conta da falta de documentação que comprovasse de fato os crimes cometidos pelas ditaduras.

Durante a década de 1990, a Condor passou a ser estudada no meio acadêmico com mais vigor graças a descoberta dos Arquivos do Terror no Paraguai, difundidos através dos estudos pioneiros de Calloni $^{5}$, Nickson $^{6}$ e Slack ${ }^{7}$. Apesar da riqueza da coleção, que permitia, por exemplo, analisar como ocorria a troca de informações entre as agências de inteligência do Cone Sul, nenhum dos documentos analisados comprovava qualquer tipo de conhecimento dos Estados Unidos sobre a Condor, fato que era alvo de polêmicas e que ganhou maior controvérsia desde o começo das investigações autorizadas pelo juiz espanhol Baltasar Garzón, responsável pela prisão de Augusto Pinochet, em 1998.

No final do governo Bill Clinton, o poder executivo estadunidense deu início ao Chile Declassification Project, projeto de liberação de arquivos secretos dos EUA relacionados à ditadura chilena, que lançaram aos pesquisadores mais de 23 mil documentos de diferentes órgãos federais, como Departamento de Estado, CIA, FBI, além das comunicações entre as Embaixadas dos países do Cone Sul com Washington. A partir destas revelações, acadêmicos iniciaram uma ampla investigação sobre a participação e o envolvimento dos Estados Unidos na Operação Condor. O livro The Pinochet File, de autoria de Peter Kornbluh, causou grande controvérsia ao compilar documentos que comprovavam o apoio de Nixon, Ford e Kissinger a ditadura chilena. ${ }^{8}$ Ao resenhar este, Maxwell ${ }^{9}$ clamou pelo maior envolvimento do meio acadêmico com a coleção de documentos, citando que era de interesse da sociedade conhecer o "outro 11 de setembro" - referência a data do golpe orquestrado por Pinochet. Neste mesmo período, a ala neoconservadora estadunidense reagiu com vigor as denúncias de Kornbluh sobre um suposto conluio dos EUA com o Chile - e, em última instância, com

\footnotetext{
${ }^{1}$ Doutorando em História (PUCRS). Bolsista do CNPq. E-mail: waldemar@dalenogare.com

${ }^{2}$ Chamado pelos integrantes das agências de inteligência de Plan Condor - homenagem proposta pela delegação uruguaia ao Chile - os registros da CIA e do Departamento de Estado utilizaram o termo Operation - que também foi popularizado pela mídia.

${ }^{3} \mathrm{O}$ termo foi constantemente empregado pelo Departamento de Estado americano e pela CIA na transição da década de 1960 para a década de 1970. Em um relatório de defesa de 1968, por exemplo, a recomendação do Conselho de Segurança Nacional dos EUA era para apoiar os regimes militares instalados na América Latina pois estava claro de que eles possuíam o know-how para lidar com subversão marxista de maneira eficaz. CIA. The Potential for Revolution in Latin America. National Intelligence Estimate 80/90-68. Base de dados CREST, 28 de março de 1968.

${ }^{4}$ CHOMSKY, Noam; HERMAN, Edward S. The Washington Connection and Third World Fascism. Quebec: Black Rose Books Ltd, 1979.

${ }^{5}$ CALLONI, Stella. Los años del lobo: Operación Cóndor. Buenos Aires: Continente, 1999, p. 17.

${ }^{6}$ NICKSON, R. Andrew. Paraguay's archivo del terror. Latin American Research Review, p. 125-129, 1995.

7 SLACK, Keith M. Operation Condor and Human Rights: A Report from Paraguay's Archive of Terror. Human Rights Quarterly, v. 18, n. 2, p. 492-506, 1996.

${ }^{8}$ KORNBLUB, Peter. The Pinochet File: A Declassified Dossier on Atrocity and Accountability. Nova York: New Press, 2013.

${ }^{9}$ MAXWELL, Kenneth. The Other 9/11. Foreign Affairs. 82, 6, 147-151, Novembro de 2003.
} 
a Operação Condor. William Rogers, secretário pessoal de Henry Kissinger, publicou uma nota de repúdio na revista Foreign Affairs onde dizia que pesquisadores como Kornbluh e Maxwell apenas davam força a retórica da esquerda intelectualizada que culpava os Estados Unidos pelos problemas econômicos e sociais que assentavam a América Latina: "in Latin America, it reinforces the instinct to blame Washington and to seek the redress of grievances there rather than at home". ${ }^{10}$

$\mathrm{Na}$ última década, no entanto, os trabalhos que investigam a Operação Condor ganharam força com as contribuições de Dinges ${ }^{11}$ e McSherry ${ }^{12}$. Dentre as revelações encontradas a partir dos arquivos liberados pelos Estados Unidos encontram-se detalhes sobre um plano feito por oficiais uruguaios para assassinar o então congressista Edward Koch, do estado de Nova Iorque, um dos principais responsáveis pela campanha contra o apoio do poder executivo às ditaduras do Cone Sul no Congresso estadunidense e criador da Emenda ao Security Assistance Act de 1977 que cortou 3 milhões de dólares de crédito militar dos Estados Unidos ao Uruguai. Mesmo sabendo de um possível atentado em solo americano contra um político local, a CIA, no primeiro momento, sequer avisou Koch sobre a ameaça. Somente após o assassinato de Orlando Letelier, também organizado pelo aparato Condor, o FBI e o Departamento de Justiça interceptaram as ameaças e atuaram para garantir a segurança do parlamentar.

A análise deste caso dentro do contexto da Operação Condor demonstra como a impunidade gerada pelo apoio de Nixon, Ford e Kissinger às ditaduras do Cone Sul deu liberdade para a Condor expandir seu viés transnacional, atuando para aniquilar as oposições locais e silenciar as vozes internacionais que denunciavam o esquema montado pelas agências de inteligência do Cone Sul.

\section{Documentação}

O caso Koch foi revelado por John Dinges, em 2004. Além de pesquisar na base de dados de arquivos sobre o Chile liberada pelos Estados Unidos, também entrou com processos de liberação de documentos secretos (Freedom of Information Act) junto ao Departamento de Estado e ao Departamento de Justiça para obter informações complementares sobre o caso. Ao tratar sobre os congressistas estadunidenses que eram contra o apoio as ditaduras do Cone Sul, López reconhece Koch como um dos principais políticos engajados na luta pela promoção de direitos humanos, com participação ativa em comissões do Congresso criadas para discutir o corte de auxílio humanitário e militar aos países cuja Anistia Internacional tinha registro sobre violações de direitos humanos. ${ }^{13}$

Além dos documentos revelados pela administração Clinton, este trabalho analisa duas outras bases de arquivos recentemente liberados para consulta. A primeira é a coleção de documentos diplomáticos lançada em 2015 pelo Office of Historian, órgão do Departamento de Estado ligado ao Bureau de Relações Públicas que é responsável por compilar e distribuir aos pesquisadores coleções de documentos desclassificados. No caso específico de Koch, aproveita-se a coleção Documents on South America, 1973-1976, da série Foreign Relations of the United States - que contém arquivos que mostram a pressão diplomática exercida por oficiais uruguaios, pelo Embaixador dos EUA no Uruguai, Ernest V. Siracusa, e pelo próprio Departamento de Estado para rejeitar a proposta de Koch. ${ }^{14}$ Também foram aproveitados documentos liberados pelo processo FOIA criado pelo autor deste

\footnotetext{
${ }^{10} \mathrm{Na}$ América Latina se reforça o instinto de culpar Washington e buscar a reparação de injustiças lá ao invés de fazer isto em casa (tradução do autor). ROGERS, William. Fleeing the Chilean Coup. Foreign Affairs. 83, 1, 160-165, Janeiro de 2004.

${ }^{11}$ DINGES, John. The Condor Years: How Pinochet And His Allies Brought Terrorism To Three Continents. Nova York: New Press, 2004.

12 MCSHERRY, J. Patrice. Predatory States: Operation Condor and Covert War in Latin America. Lanham: Rowman \& Littlefield Publishers, 2012.

${ }^{13}$ LÓPEZ, Fernando. The Feathers of Condor: Transnational State Terrorism, Exiles and Civilian Anticommunism in South America. Cambridge: Cambridge Scholars Publishing, 2016, p. 204.

${ }^{14}$ OFFICE of Historian. Foreign Relations of the United States, 1969-1976, Volume E-11, Part 2, Documents on South America, 1973-1976. 2015. Disponível em: https://history.state.gov/historicaldocuments/frus1969-76ve11p2. Acesso em 11 jun. 18. 
artigo $^{15}$ sobre violações de direitos humanos no Uruguai que contém detalhes adicionais sobre a ação das agências federais estadunidenses durante o caso Koch.

\section{A Operação Condor e a administração Nixon/Ford}

Congressista pelo estado de Nova Iorque desde 1969, Ed Koch e demais políticos do Partido Democrata contrários ao apoio dos Estados Unidos aos regimes do Cone Sul começaram a pressionar a Casa Branca e o Departamento de Estado em 1974, com as primeiras denúncias de abusos do regime Pinochet enviadas ao Congresso e encaminhadas para comissões específicas - com destaque para a de Relações Internacionais.

Na gênese da Operação Condor, a união das agências de inteligência e militares do Cone Sul começou em 1973, com a criação da DINA (Dirección de Inteligencia Nacional), a polícia secreta de Pinochet comandada por Manuel Contreras, agente repressivo treinado pelos estadunidenses na Escola das Américas responsável pelo estreitamento de relações entre os serviços secretos de Brasil, Chile, Paraguai e Uruguai e com a área de inteligência do Exército da Argentina e da Bolívia. O assassinato do General Carlos Prats, Comandante das Forças Armadas e Ministro do Interior de Salvador Allende, planejado pela DINA e executado em parceria com oficiais argentinos em Buenos Aires, foi o primeiro teste para o protótipo da Condor. Com pouca repercussão internacional, os militares do Cone Sul apostaram na expansão das atividades, com a criação de um sistema de troca de informações (Condortel) instalado com auxílio dos Estados Unidos. ${ }^{16}$ A CIA omitiu informações sobre o assassinato de Prats durante duas, três décadas, e a abertura dos arquivos da agência mostrou que o General era visto como principal rival de Pinochet pelo Exército chileno. ${ }^{17}$ De setembro de 1973 até sua morte, em setembro de 1974, a CIA confeccionou documentos sobre a rotina de Prats e sobre suas possíveis aspirações políticas. Um mês antes do golpe militar no Chile, a CIA já identificava Prats como um militar legalista e já identificava ameaças de morte:

Army Commander Prats remains the prime obstacle. He is so strongly opposed to a coup that he reportedly has told troops to obey their commanders if they are ordered to participate in any move against the government. None of the plotters appears to have a viable scheme for getting around Prats but the present level of tension is such that another desperation move is possibly directed against Prats as well as the government, is a continuing possibility. ${ }^{18}$

O assassinato de Prats foi um marco que consagrou a política de silêncio estabelecida pela Casa Branca de Richard Nixon e pelo Departamento de Estado liderado por Henry Kissinger. As violações de direitos humanos cometidas pelos regimes do Cone Sul eram mascaradas na retórica da guerra contra o comunismo. Desaparecidos eram considerados terroristas nas atas das Embaixadas enviadas ao Departamento de Estado, e o auxílio humanitário e militar dos Estados Unidos aos regimes do Cone Sul aumentou exponencialmente durante 1973 e 1974 para financiar os friends of the american way. ${ }^{19}$

O fortalecimento dos laços entre os setores de inteligência dos países da Condor expandiu com a criação de equipes de especialistas encarregadas por missões classificadas como

\footnotetext{
${ }^{15}$ Freedom of Information Act O-20xx-03444 junto ao Departamento de Estado.

${ }^{16}$ Departamento de Estado dos Estados Unidos. Cable, U.S. Ambassador Robert White (Paraguay) to Secretary of State Cyrus Vance. 1978.

${ }^{17}$ CIA. Prats. 27 de novembro de 1973.

${ }^{18}$ O Comandante do Exército Prats permanece como principal obstáculo. Ele é totalmente contra a ideia de golpe que teria dito às tropas que obedecessem a seus comandantes se fossem ordenados a participar de qualquer ação contra o governo. Nenhum dos golpistas parece ter um esquema viável para contornar Prats, mas o atual nível de tensão é tal que outra ação desesperada possivelmente dirigida contra Prats, assim como ao governo, é uma possibilidade contínua. CIA. Consequences of a Military Coup in Chile. 1 de Agosto de 1973.

${ }^{19}$ Amigos do american way. HAWKINS, Darren G. International Human Rights and Authoritarian Rule in Chile. Lincoln: U of Nebraska Press, 2002, p. 98.
} 
"essenciais" para a Operação. Bernardo Leighton, político chileno exilado em Roma e grande crítico da ditadura de Pinochet foi o primeiro alvo dos especialistas - que gozavam de vastas verbas do governo chileno. A malograda tentativa de assassinato de Leighton, em outubro de 1975, demonstrou falhas no modus operandi pensado por Manuel Contreras, chefe da DINA.

A Operação Condor tornou-se oficial na reunião de 28 de novembro de 1975 em um encontro denominado Primera Reunión Interamericana de Inteligencia - com uma ata assinada por líderes dos setores de inteligência de Argentina, Bolívia, Chile, Paraguai e Uruguai, com dois representantes brasileiros como observadores. ${ }^{20}$ Foram estabelecidos objetivos divididos em três fases para ampliar a parceria e cooperação transnacional, facilitando o fluxo de informações sobre opositores políticos com o objetivo de silenciar as principais vozes de oposição aos regimes do Cone Sul em qualquer lugar da América do Sul.

Tanto a CIA como o Departamento de Estado tinham pleno conhecimento das intenções dos países da Condor. Em relatório interno, a agência estadunidense notou a ausência da assinatura do Brasil no encontro de novembro 1975, destacando a importância estratégica do país para o Condortel. ${ }^{21}$ Ao analisar os objetivos da Condor, o Departamento de Estado de Kissinger também tinha informações de planos de militares do Cone Sul para atacar alvos políticos na Europa por conta da parceria da DINA com grupos neofascistas e anticomunistas, com destaque para o acordo celebrado com a Avanguardia Nazionale, de Stefano Delle Chiaie. $^{22}$ Além disso, a CIA registrava em suas atas internas que ex-agentes passaram a trabalhar para os serviços de inteligência do Cone Sul, especialmente para a DINA. O mais famoso deles, Michael Townley, orquestrou o assassinato de Prats e transitava livremente nos Estados Unidos com passaportes falsos, difundindo técnicas de Terrorismo de Estado adquiridas em cursos financiados pela própria CIA durante a década de $1960 .^{23}$

Mesmo com registros de ameaça de assassinatos e de violações de direitos humanos cometidas pelos países da Condor, o poder executivo estadunidense durante a administração Nixon/Ford jamais cogitou cortar verbas ou pressionar estes países. ${ }^{24}$ Quando Robert C. Hill, Embaixador dos Estados Unidos na Argentina, passou a questionar a carta branca dada por Kissinger aos crimes cometidos pelas ditaduras do Cone Sul a partir da elaboração de uma ata que buscava pressionar o então presidente argentino, Jorge Videla, a demonstrar avanços na questão dos direitos humanos, o mesmo foi desautorizado pelo Departamento de Estado. ${ }^{25}$ No mesma época, Kissinger garantiu ao Chanceler argentino César Guzzetti o apoio dos Estados Unidos no que classificava de "guerra contra o terrorismo" ao pronunciar "We want you to succeed (...) If there are things that have to be done, you should do them quickly". ${ }^{26}$

\footnotetext{
${ }^{20}$ DINA. Acta de clausura de la primera reunión interamericana de inteligencia nacional. 28 de novembro de 1975. Em 2010, Luiz Cláudio Cunha revelou que o Brasil foi representado no encontro pelo coronel Flávio de Marco e pelo major Thamaturgo Sotero Vaz. Ver CUNHA, Luiz Cláudio. Operação Condor: o sequestro dos uruguaios. Porto Alegre: L\&PM, 2010.

${ }^{21}$ CIA. Brazil Report. 11 de março de 1976.

${ }^{22}$ Em 1982 o FBI considerou Delle Chiaie como o principal responsável pela troca de informações e difusão de práticas criminosas do Chile na Europa durante a década de 1970. FBI. DINA. 21 de janeiro de 1982.

23 Parte dos documentos secretos da CIA sobre Townley não foram abertos ao público por conta da entrada deste no programa de proteção a testemunhas do governo estadunidense.

${ }^{24}$ Em 1977, por exemplo, a CIA notou a existência de planos da Operação Condor para assassinar membros da Anistia Internacional envolvidos nas investigações sobre violações de direitos humanos em países do Cone Sul. O registro foi arquivado e a Anistia Internacional não foi notificada. CIA. Counterterrorism in the Southern Cone. 9 de maio de 1977.

${ }^{25}$ Ver Departamento de Estado dos Estados Unidos. Telegram 3462 From the Embassy in Argentina to the Department of State. 25 de maio de 1976; e Departamento de Estado dos Estados Unidos. Murders in Argentina - no intergovernment conspiracy. 4 de junho de 1976.

${ }^{26}$ Queremos que você tenha sucesso (...) Se há coisas que precisam ser feitas, você deve fazê-las rapidamente. Departamento de Estado dos Estados Unidos. Memorandum of Conversation between Secretary of State Henry Kissinger and Argentine Foreign Minister Adm. Cesar Guzzetti. 10 de julho de 1976.
} 
O interesse empresarial também teve forte impacto dentro da agenda estadunidense no intuito de garantir o apoio de diplomatas e oficiais aos regimes ditatoriais do Cone Sul. Financiamentos do Banco Interamericano de Desenvolvimento para Argentina, Chile $e$ Uruguai cresceram exponencialmente a partir de 1973; vendas militares para estes mesmos países atingiram os maiores números da história; e empresários estadunidenses recebiam forte apoio diplomático para estabelecer e ampliar negócios nestes países - especialmente com a instalação de franquias graças aos financiamentos do Export-Import Bank of the United States. ${ }^{27}$

A omissão do governo estadunidense nas violações de direitos humanos no Cone Sul ainda empregava uma retórica de não interferência falaciosa. Quando pressionados pela imprensa, membros da Casa Branca e do Departamento de Estado diziam estar comprometidos com avanços na América Latina ao mesmo tempo que elogiavam publicamente avanços econômicos das ditaduras. Também foi característica do governo Nixon/Ford, o boicote dos EUA em todas votações na Organização das Nações Unidas que visavam condenar os regimes do Cone Sul por violações de direitos humanos, ainda que estas tenham sido aprovadas posteriormente na Assembleia Geral. ${ }^{28}$

\section{O Congresso e a Operação Condor}

O escândalo Watergate, o subsequente perdão presidencial concedido por Ford a Nixon e o desenrolar da Guerra do Vietnã foram responsáveis por mudanças na Câmara dos Representantes dos Estados Unidos. Os republicanos perderam 48 cadeiras e os democratas ganharam 49 para a composição do Congresso de 1975. Essa geração de políticos jovens do Partido Democrata é conhecida na historiografia por Watergate Babies - termo que ressalta que grande parte dos eleitos para compor o $95^{\circ}$ Congresso não teriam chances reais de vitória antes da renúncia de Nixon. ${ }^{29}$

Com o controle da Casa dos Representantes pelo Partido Democrata, os Babies tiveram fundamental importância para ampliar a discussão sobre o apoio as ditaduras do Cone Sul. Até 1976, a única ação concreta do poder legislativo foi a proibição de venda de armas ao Chile no Foreign Assistance Act of $1974 .{ }^{30}$ Iniciativas anteriores, como a comissão do Senado de Ted Kennedy para a investigação de abusos no Chile foram canceladas por falta de quórum por conta do domínio republicano no Congresso.

Somente em 1975, com a abertura da comissão parlamentar do Comitê de Relações Internacionais de investigação de violações de direitos humanos, o Congresso passou a pressionar o Departamento de Estado a demonstrar o nível de comprometimento da Casa Branca e da diplomacia estadunidense com os militares do Cone Sul. ${ }^{31}$ No entanto, dentro da perspectiva da realpolitik de Henry Kissinger, levando em conta a teoria da balança de poder no mundo bipolar, o Departamento de Estado considerava que os novos congressistas democratas abraçavam propostas humanitárias que enfraqueciam a dinâmica de poder dos Estados Unidos. Investigações sobre os recursos enviados para Argentina, Chile, Coreia do Sul, Indonésia, Irã, República do Congo, Tailândia e Uruguai esbarravam

\footnotetext{
27 LOWENTHAL, Abraham. Exporting democracy: the United States and Latin America. Baltimore: Johns Hopkins University, 1991, p. 109.

${ }^{28}$ MARTIN, Lisa. Coercive Cooperation: Explaining Multilateral Economic Sanctions. Princeton: Princeton University Press, 1994, p. 124.

29 ZELIZER, Julian. On Capitol Hill: The Struggle to Reform Congress and Its Consequences, 1948-2000. Cambridge: Cambridge University Press, 2006, pp. 156- 176.

${ }^{30}$ Deve-se ressaltar, no entanto, que o auxílio dos Estados Unidos ao Chile durante a administração Nixon/Ford foi alocado no orçamento de recursos humanitários. Ver RENOUARD, Joe. Human Rights in American Foreign Policy: From the 1960s to the Soviet Collapse. Filadélfia: University of Pennsylvania Press, 2016, p. 80.

${ }^{31}$ A investigação liderada por Koch teve seu foco voltado para o Uruguai. Para os resultados, ver Congresso dos Estados Unidos. Human Rights in Uruguay and Paraguay: Hearings Before the Subcommittee on International Organizations of the Committee on International Relations. Washington: U.S. Government Printing Office, 1976.
} 
na falta de apoio de parlamentares republicanos, que esvaziavam sessões e não aceitavam tal nível de interferência do poder legislativo nas decisões do executivo.

Após Gerald Ford vetar uma lei que barrou a venda de armas para a Indonésia, os Babies foram responsáveis pela criação de propostas que enfraqueceriam o decision-making do Departamento de Estado, restringindo o alcance e destino dos recursos transferidos por ordem da Casa Branca aos países que a Anistia Internacional classificava como repressivos e violadores de direitos humanos. Ainda em 1975, dois projetos do Congresso afetaram diretamente a Operação Condor: o primeiro foi a exigir do Departamento de Estado a produção anual de relatórios reportando a situação dos direitos humanos nos países que recebiam auxílios dos Estados Unidos, sendo que os recursos apenas poderiam ser mantidos após aval das Comissões de direitos humanos do Congresso. ${ }^{32}$ Outra medida foi o limite de transferência de recursos dos Estados Unidos para o Chile para o teto de 1 milhão de dólares por ano, além do veto às vendas de armamentos. ${ }^{33}$

Durante todo período da Operação Condor, nenhuma comissão do Congresso e nenhum congressista foi alertado pelo Departamento de Estado ou por outra agência federal sobre a existência do pacto entre os países do Cone Sul. Tal fato, que pode ser entendido como uma manobra de obstrução coordenada por Henry Kissinger para diminuir o impacto da pressão do legislativo nos auxílios humanitários e militares - verbas essenciais para o combate ao comunismo na retórica proposta pela Casa Branca - afetaram os estudos feitos pelas comissões, que não entregavam resultados conclusivos sobre o nível de influência e interferência da diplomacia do Departamento de Estado no Cone Sul.

Com discussões em curso sobre a possibilidade de criação de comissões para investigar Argentina $e$ Chile, o congressista democrata Ed Koch demonstrou interesse na situação do Uruguai após receber um comunicado da Anistia Internacional enviado ao Congresso sobre a gravidade da situação do país após a posse de Juan María Bordaberry. Segundo os números apresentados por Koch no Congresso em 1976, ao menos 60 mil uruguaios haviam sido presos desde o início da ditadura - e a organização caracterizava o país como o mais repressivo do mundo.

Koch, portanto, foi o primeiro congressista a denunciar os abusos do governo uruguaio no plenário estadunidense. Durante sua participação no comitê de relações internacionais da Casa dos Representantes, Koch classificou o Uruguai como a "casa de tortura da América Latina" - em um forte discurso pautado pelos estudos da Anistia Internacional, que ainda lembrava que o país estava superando o Chile no número de denúncias de violações dos direitos humanos, mesmo que com uma população três vezes menor. Durante as discussões feitas no comitê liderado pelo congressista Clarence Long, Koch pediu ao Departamento de Estado informações sobre o destino dos milhões de dólares transferidos ao Uruguai desde o começo da administração Nixon, além de questionar diretamente Kissinger sobre o apoio dos EUA à ditadura uruguaia. ${ }^{34}$

Em resposta oficial ao comitê, o Departamento de Estado posicionou-se surpreso com as denúncias de violações de direitos humanos no Uruguai, e anexou um relatório no qual dizia ter convicção de que o dinheiro do fundo humanitário estava sendo utilizado para a melhoria da infraestrutura do país. Sem ter acesso aos documentos secretos da CIA e do próprio Departamento de Estado, Koch usou a argumentação do comunicado do Departamento de Estado para anunciar a criação de uma emenda ao Security Assistance Act de 1977 para proibir a transferência de recursos ao Uruguai:

In the past year I have come to fully comprehend the terror that the Uruguayan regime is inflicting upon its own people. I have also learned that the State Departament, regrettably, is not as much aware of that situation. This cut-off of military assistance to Uruguay will hopefully set U.S policy toward that country straight: we are not going to

\footnotetext{
32 Os dois relatórios lançados durante a gestão Ford foram duramente criticados pela Anistia Internacional e pela Freedom House por omitir denúncias consolidadas sobre violações de direitos humanos. No caso da Operação Condor, o Departamento de Estado omitiu seus registros sobre a parceria dos países do Cone Sul. Ver HEVENER, Natalie. The Dynamics of Human Rights in United States Foreign Policy. Piscataway: Transaction Publishers, 1981.

${ }^{33}$ ENSALACO, Mark. Chile Under Pinochet: Recovering the Truth. Filadélfia: University of Pennsylvania Press, p.160.

${ }^{34}$ Congresso dos Estados Unidos. House Reports: United States Congressional Serial Set, Volumes 13134 - 38. Washington: U.S. Government Printing Office, 1976, pp. 57 - 59.
} 
assist the Uruguayan military regime in the repression of its own people. While the amount of assistance - $\$ 3$ million - is modest, the prohibition is an important precedent. The Uruguayan regime is not alone as the oppressor of its own people. Chile, Brazil, Argentina and other nations in Latin America seem to have no regard for the basic human rights of their peoples. This cut-off should send a message to those regimes as well. $^{35}$

A emenda Koch proibia o repasse de três milhões de dólares do orçamento do Departamento de Defesa. Para Koch, sua ação no Congresso deveria ser vista como um complemento da emenda Harkin - que proibia o Banco Interamericano de Desenvolvimento de emprestar dinheiro para governos classificados como repressivos pelas comissões legislativas competentes - e mostraria à Casa Branca que o legislativo não concordava com a constante transferência de recursos dos EUA aos países que não eram comprometidos com a promoção dos direitos humanos, ameaçando desconstruir o projeto de equilíbrio de poder de Kissinger não apenas no Cone Sul, mas também na África e na Ásia. ${ }^{36}$

Durante o encaminhamento da emenda no Congresso, Koch também abriu uma moção para condenar publicamente o Uruguai por violações dos direitos humanos. Junto do Senador Ted Kennedy, Koch patrocinou a Resolução 120 - que abria a possibilidade de asilo aos perseguidos políticos uruguaios, facilitando o burocrático processo de obtenção de visto. ${ }^{37}$

Desde o anúncio da criação da emenda Koch, a tramitação do texto do Security Assistance Act de 1977 no Congresso sofreu forte interferência do Departamento de Estado. Quando informado sobre o possível corte no auxílio ao Uruguai, o Embaixador dos EUA no país, Ernest V. Siracusa, identificou a emenda como forte empecilho para o fortalecimento do laço entre os dois países. Cita o Embaixador em sua primeira manifestação à Kissinger sobre a Emenda Koch:

We believe the action to have been ill-founded, first because of a false impression as to the Uruguayan situation and second because such a measure, if enacted, would adversely affect other US interests without changing the situation it is intended to correct. We recommend that the department ensure that the committee receive a portrayal of the situation as reported in depth by the Embassy. ${ }^{38}$

Indicado por Nixon para ocupar o posto de Embaixador logo após a posse Bordaberry, Siracusa pressionava o Departamento de Estado também pela sua forte relação com os militares uruguaios, comprovada em despachos de 1973 que elogiavam a coragem para tomar decisões fortes para reposicionar o Uruguai como destaque da América do Sul. O diplomata também tinha conhecimento da Operação Condor, e ainda assim, evitava detalhes sobre a parceria entre os serviços de inteligência

\footnotetext{
${ }^{35}$ No último ano eu passei a compreender plenamente o terror que o regime uruguaio está infligindo sobre seu próprio povo. Eu também aprendi que o Departamento de Estado, lamentavelmente, não está tão atento neste caso. Esse corte da assistência militar ao Uruguai deixará clara a política americana em relação àquele país: nós não vamos ajudar o regime militar uruguaio na repressão de seu próprio povo. Embora o montante de assistência - 3 milhões de dólares - seja modesto, a proibição é um precedente importante. O regime uruguaio não está sozinho como o opressor de seu próprio povo. Chile, Brasil, Argentina e outras nações da América Latina parecem não ter consideração pelos direitos humanos básicos de seus povos. Este corte deve enviar uma mensagem para esses regimes também. Ver PASTOR, Robert. Congress and the Politics of U.S. Foreign Economic Policy, 1929-1976. Berkeley: University of California Press, 1982, p. 312.

${ }^{36}$ A Emenda Harkin sofreu forte resistência do governo Ford, mas não foi vetada após a aprovação no Congresso pelo fato da Casa Branca não ter votos suficientes para manter o veto. Foi assinada como Lei Pública 94-302 em 31 de maio de 1976.

${ }^{37}$ Congresso dos Estados Unidos. House Resolution 120. 1976.

${ }^{38}$ Nós acreditamos que a ação foi infundada, primeiro por causa da falsa impressão quanto à situação uruguaia e, segundo, porque tal medida, se promulgada, afetaria adversamente outros interesses dos EUA sem alterar a situação que pretende corrigir. Recomendamos que o Departamento assegure que o comitê receba uma descrição da situação conforme relatado em detalhes pela Embaixada. Embaixada dos Estados Unidos no Uruguai. Telegram 1610 From the Embassy in Uruguay to the Department of State. 7 de maio de 1976. Disponível em: https://1991.history.state.gov/historicaldocuments/frus196976ve11p2/d348. Acesso em: 11. jun. 18.
} 
do Cone Sul..$^{39}$ Além disso, Siracusa patrocinava uma operação em conjunto com a Embaixada dos EUA no Chile para diminuir o impacto das violações de direitos humanos em seus respectivos países. Anticomunista e conservador, Siracusa escreveu cartas a punho para que membros do Congresso não interrompessem a relação de amizade dos EUA com o Uruguai, citando que o possível corte de verbas seria encarado pelos militares de forma extremamente negativa.

A ala republicana no Congresso atuou para tirar a Emenda Koch da pauta do Security Assistance Act de 1977 com apoio do poder executivo. Durante uma das sessões de discussão da Emenda Koch, congressistas republicanos apresentaram uma carta repúdio na qual o governo uruguaio negava categoricamente o uso da tortura. Como resposta, o congressista Donald Fraser - um dos principais apoiadores da tramitação da Emenda Koch - perguntou aos colegas republicanos se eles conheciam algum país no mundo que havia admitido publicamente o uso da tortura. ${ }^{40}$

A tentativa de cancelar as sessões de discussão da Emenda Koch apenas aumentou o interesse do Partido Democrata em torno da puta. Os seis congressistas do partido na Comissão de Relações Internacionais aprovaram a Emenda, que ainda teve quatro votos contrários. Antes da apreciação da proposta no plenário, Koch passou a criticar publicamente Siracusa, apontando um possível conluio do Embaixador com os militares uruguaios. No mesmo período, Koch reuniu-se com Wilson Ferreira Aldunate, ex-Senador uruguaio que foi alvo da Operação Condor ${ }^{41}$, que também acreditava que Siracusa estava empenhado em defender a ditadura uruguaia a qualquer custo. O político participou de sessões no legislativo na qual denunciou os crimes da ditadura de seu país, citando a participação de oficiais estadunidenses na organização da comunicação dos sistemas de inteligência do Cone Sul.

Preocupado com a possível interferência de Koch na eleição presidencial de outubro, Kissinger ordenou a Siracusa a escrita de uma carta na qual o mesmo dizia servir apenas ao governo estadunidense. No entanto, tal nota de repúdio as declarações de Ferreira e Koch jamais foi lida no Congresso. $^{42}$

Ainda assim, Siracusa organizou a última tentativa de barrar o corte de três milhões de dólares ao Uruguai ao patrocinar publicamente a iniciativa do Comitê de Relações Internacionais do Senado de vetar o corte proposto por Koch. Apesar de ser liderado por um Senador do Partido Democrata, Daniel Inouye, a maioria do comitê acreditava que o corte no ano de 1977 não poderia ocorrer meses antes das eleições nos Estados Unidos. Apesar da comissão do Senado chegar a um acordo para votar esse veto, Inouye desistiu da proposta após o testemunho de Ferreira Aldunate no Senado, onde mais uma vez renovou as críticas ao Departamento de Estado dos EUA, ao Embaixador Siracusa e ao governo uruguaio. Como tentativa final, Siracusa enviou um comunicado a Kissinger pedindo interferência do Departamento de Estado para evitar a aprovação da Emenda Koch:

I have just learned that a version of the Koch amendment has been introduced into the Senate bill. Since I am leaving later today and will not be in Washington for about a couple of weeks I wish to stress to you most emphatically and sincerely that I believe the passage of this amendment can do serious damage to our relations with Uruguay and, no matter how well intended it may be, is likely to have a counter-productive effect; that is, instead of helping the situation regarding human rights in this country it is

\footnotetext{
${ }^{39}$ Siracusa rejeitou por três vezes a ideia de que as agências de inteligência do Cone Sul pudessem estar reunidas em torno da perseguição de dissidentes políticos. Em 1976, pressionado por Washington, admitiu a existência da Condor apenas quando o Departamento de Estado considerou, por um breve período, deixar de apoiar o sistema de troca de informações tendo em vista a eleição presidencial de 1976. Ver Embaixada dos Estados Unidos no Uruguai. Telegram 3123 From the Embassy in Uruguay to the Department of State. 24 de agosto de 1976.

40 Congresso dos Estados Unidos. Human Rights in Uruguay and Paraguay: Hearings Before the Subcommittee on International Organizations of the Committee on International Relations. Washington: U.S. Government Printing Office, 1976.

${ }^{41}$ Ferreira Aldunate escapou da morte ao se refugiar na Embaixada da Áustria em Buenos Aires tão logo recebeu a informação de que agentes uruguaios estavam sequestrando alvos políticos. Seu colega de Senado, Zelmar Michelini e o deputado Héctor Gutiérrez Ruiz foram capturados, torturados e assassinados na capital argentina. Desde então, Ferreira tornou-se o principal opositor do regime militar no Uruguai.

42 Para um resumo das comunicações, ver Embaixada dos Estados Unidos no Uruguai. Telegram 2722 From the Embassy in Uruguay to the Department of State. 21 de julho de 1976 . Disponível em: https://history.state.gov/historicaldocuments/frus1969-76ve11p2/d355. Acesso em 11 jun.18 
likely because of its punitive and condemnatory nature to produce such a reaction as to have a harmful effect on what we believe to be a clear trend toward improvement. I hope the Department can bear these factors in mind in making a vigorous effort to see to it that the Koch amendment does not become law. (....) As a final point I would like to reiterate that in our opinion, the accusations against Uruguay which have inspired this legislation are to a considerable extent exaggerated and inaccurate. ${ }^{43}$

O apelo de Siracusa não foi considerado por Kissinger pela proximidade da eleição presidencial entre Gerald Ford e Jimmy Carter, considerando que o Departamento de Estado acreditava que a pauta de direitos humanos poderia favorecer o candidato democrata. Entre 21 e 28 de setembro de 1976, o Congresso estadunidense discutiu a resolução a Emenda Koch dentro da Resolução 14260 que foi aprovada na Casa dos Representantes e no Senado. Também pelo contexto da eleição presidencial, Ford aprovou e assinou a lei pública 94-441. Segundo o texto:

PL 94 -441. SEC. 505. None of the funds appropriated or made available pursuant to this Act shall be used to provide military assistance, international military education and training, or foreign military credit sales to the Government of Uruguay. ${ }^{44}$

\section{O aparato Condor contra Koch}

Durante o auge da Operação Condor, entre 1974 e 1976, o governo uruguaio atuou ativamente na perseguição de dissidentes políticos. Com as mortes de Zelmar Michelini e Héctor Gutiérrez Ruiz, dois dos principais críticos da ditadura uruguaia, a Condor colocou Koch na lista de alvos após a insistência do congressista em lançar sua emenda para o ano fiscal de 1977.

Durante o período em que Koch se destacava no Congresso ao patrocinar as sessões com relatos de vítimas da repressão uruguaia, Frederick Latrash, chefe da estação da CIA em Montevidéu, recebeu a informação de que dois oficiais de alta patente no exército uruguaio estavam extremamente insatisfeitos com a emenda Koch e ameaçaram matar o congressista em uma tentativa desesperada de interromper seu projeto de lei. Latrash provavelmente não transmitiu essa informação para seu superior, o Embaixador Ernest Siracusa ${ }^{45}$, e arquivou a ameaça em um documento ultrassecreto enviado apenas à CIA e depositado nos arquivos após este ser tema de uma reunião do então diretor da agência, George H.W. Bush. No mesmo período, Siracusa tentou articular com o Departamento de Estado uma possível visita de Koch ao Uruguai para tentar mudar o posicionamento do político ao planejar reuniões com altas autoridades do país. ${ }^{46}$

\footnotetext{
${ }^{43}$ Acabei de tomar conhecimento de que uma versão da emenda Koch foi introduzida como projeto de lei do Senado. Já que estou partindo hoje e como não estarei em Washington em duas semanas, quero dizer de maneira sincera e enfática que eu acredito que a aprovação dessa emenda pode causar sérios danos às nossas relações com o Uruguai e, não importa quão bem intencionada ela é, esta pode ter um efeito contrário; ou seja, em vez de ajudar a situação em relação aos direitos humanos neste país, é bem provável a natureza punitiva e condenatória desta produza uma reação que tenha um efeito prejudicial sobre o que acreditamos ser uma clara tendência de melhoria. Espero que o Departamento tenha em mente esses fatores para fazer um esforço vigoroso para garantir que a emenda Koch não se torne lei. (...) Como último ponto, gostaria de reiterar que, em nossa opinião, as acusações contra o Uruguai que inspiraram esta legislação devem ser consideradas exageradas e imprecisas. Embaixada dos Estados Unidos no Uruguai. Telegram 3462 From the Embassy in Uruguay to the Department of State. 16 de setembro de 1976. Disponível em: https:/history.state.gov/historicaldocuments/frus196976ve11p2d362 Acesso em: 11 jun.18

${ }^{44}$ PL 94 - 441. SEC. 505. Nenhum dos fundos apropriados ou disponibilizados nos termos desta Lei serão utilizados para fornecer assistência militar, educação militar internacional e treinamento, ou vendas de créditos militares estrangeiros ao Governo do Uruguai. Estados Unidos da América. Lei Pública 94-441. Assinada por Gerald Ford em 1 de outubro de 1976. Disponível em: https:/www.gpo.gov/fdsys/pkg/STATUTE-90/pdf/STATUTE-90-Pg1465.pdf. Acesso em: 11.jun.18

${ }^{45}$ Também existe a possibilidade de Siracusa não ter registrado tal fato por vontade própria. De qualquer forma, não existe menção nos arquivos da Embaixada dos EUA no Uruguai sobre qualquer reação de Siracusa ao relato de Latrash. Um pedido específico de liberação de arquivos sobre a relação da Embaixada dos EUA no Uruguai com o caso Koch, feito pelo autor deste artigo e encaminhado à CIA e ao Departamento de Estado, teve como resposta a inexistência de qualquer documentação suplementar ainda protegida.

${ }^{46}$ Quando confrontado por Dinges sobre a coincidência do convite de Koch ao Uruguai com as ameaças relatadas por Latrash, Siracusa garantiu não ter conhecimento sobre qualquer ameaça à vida de Koch naquela época.
} 
No relato de Latrash, José Fons, líder do Servicio de Información de Defensa e conhecido dos estadunidenses por negociar contratos militares e José Gavazzo, chefe da SIDE na Argentina, ambos protagonistas no posicionamento do Uruguai dentro da Operação Condor juraram a morte de Koch durante a festa de aposentadoria do Coronel Raul Garibay, em julho de 1976, posicionando a Emenda Koch como uma afronta a relação de amizade dos Estados Unidos com o Uruguai. Fons argumentava aos colegas estadunidenses que era extremamente desagradável notar que os esforços da Casa Branca para financiar os regimes simpáticos ao american way estavam sofrendo sabotagem por congressistas estadunidenses que patrocinavam pautas humanitárias que não levavam em conta o contexto da disputa de poder existente no Cone Sul, lembrando a retórica usada por Richard Nixon de que era missão dos Estados Unidos garantir de todas as formas possíveis um continente americano livre da influência comunista, sem espaço para uma nova Cuba ou para a chegada ao poder de um político articulado como Salvador Allende.

O planejamento do ataque à Koch era plausível e estava de acordo com o modus operandi da Operação Condor. Fons e Gavazzo tinham viagem marcada para os Estados Unidos, onde assumiriam funções dentro da Embaixada do Uruguai em Washington e arquitetariam de lá o atentado, possivelmente em parceria com a DINA, que já mantinha uma divisão ativa na capital estadunidense.

Apesar da notificação de Latrash à CIA de uma ameaça contra a vida de Koch, a agência não atuou para proteger a vida do congressista. O Departamento de Estado, que, por sua vez, tinha em mãos indícios de que a Operação Condor expandiria seus ataques em 1976, considerou interromper o suporte ao sistema Condortel $e$ até mesmo planejou uma démarche ${ }^{47}$ para evitar ataques que pudessem comprometer a campanha presidencial de Gerald Ford, mas os planos foram cancelados por ordem de Henry Kissinger. ${ }^{48}$

O plano uruguaio para assassinar Koch foi interrompido por conta de outra atuação da Operação Condor, que vitimou Orlando Letelier e sua assistente, Ronni Karpen Moffitt, em Washington, D.C, em setembro de 1976. O atentado organizado pela DINA envolveu uma complexa operação para enviar Michael Townley aos Estados Unidos e armar a bomba no carro de Letelier sem deixar vestígios aparentes que pudessem estabelecer uma relação direta do atentado com Pinochet a curto prazo. ${ }^{49}$

A partir da entrada do FBI na investigação do caso Letelier, a agência também interceptou relatos de ameaças de morte à Koch. Ao contrário da CIA, o FBI decidiu alertar o congressista e comunicou a Casa Branca e o Departamento de Justiça sobre o perigo de um novo atentado em território estadunidense. Quando Koch cobrou a CIA por não ter lhe alertado sobre a ameaça, tendo em conta que essa seria uma das funções da agência, o então diretor, George H.W. Bush justificou que os uruguaios estavam fazendo piada e que não deveriam ser levados a sério.

Com a proximidade da eleição presidencial, o Departamento de Estado e a CIA mudaram completamente sua visão sobre a Operação Condor, deixando de apoiar o Condortel. Somente após o caso Letelier Koch foi alertado formalmente por George H.W. Bush sobre a existência do plano organizado pelos uruguaios. O posicionamento oficial da CIA, no entanto, foi entregue à Koch apenas em 2001, com o ressurgimento do interesse no caso.

The agency obtained information that during a social event in late July 1976, a Latin American military official, reportedly in state of intoxication, commented that the military was extremely irritated with your proposed amendment to restrict U.S military assistance to Latin American countries due to alleged human rights violations by the

\footnotetext{
47 Departamento de Estado dos Estados Unidos. Telegram 209192 From the Department of State to the Embassies in Argentina, Uruguay, Chile, and Bolivia. 23 de Agosto de 1976. Disponível em: < https://history.state.gov/historicaldocuments/frus1969-76ve11p2/d241 > Acesso em: 11. jun. 18.

${ }^{48}$ Departamento de Estado dos Estados Unidos. Telegram 4526 From the Embassy in Costa Rica to the Department of State. 20 de setembro de 1976. Disponível em: https://history.state.gov/historicaldocuments/frus1969-76ve11p2/d245. Acesso em: 11. jun. 18.

${ }^{49}$ Durante o governo Carter a investigação sobre a morte de Letelier feita pelo Deparatmento de Justiça culpou Michael Townley pelo incidente. Em 1993, os chilenos Manuel Contreras e Pedro Espinoza Bravo foram condenados pelo planejamento do assassinato. Pinochet não foi acusado pela falta de provas que apontassem sua ligação ao assassinato. Arquivos liberados pela CIA entre 2015 e 2017, no entanto, apontam que oficiais de inteligência estadunidense obtiveram a confirmação de Contreras, em 1978, de que Pinochet foi quem deu o sinal verde para a operação.
} 
military. This military official is also reported to have remarked that maybe he "would have to send someone to the U.S to get Congressman Koch". The agency's initial analysis of these comments was that they represented nothing more than alcoholinduced bravado. ${ }^{50}$

O Departamento de Estado, por sua vez, decidiu abrir uma investigação interna para apurar o teor das ameaças à Koch. Kissinger solicitou a Siracusa um relatório ultrassecreto sobre o caso. A resposta do Embaixador contém informações de um agente uruguaio, que garantiu que se o plano para assassinar Koch fosse levado adiante, Gavazzo seria o responsável:

His view that in the event Uruguay were to decide to go ahead with such a thing, they would entrust the operation "to only one person, Major Gavazzo"; and their modus operandi, he said, would be to send him into the United States for a few months to develop the "operational plan." 51

Siracusa ainda apontou que, por conta do caso Letelier, o Uruguai jamais se colocaria em uma posição de risco neste nível. Ao comentar sobre o fato de Fons e Gavazzo estarem de mudança para os Estados Unidos, o informante de Siracusa argumentou os apontamentos eram "uncoincidental and neither will have a Condor Mission.". 52

\section{Considerações finais}

A contradição da CIA, do Departamento de Estado e de Siracusa sobre o caso Koch pode ser testemunhada a partir da análise de documentos liberados recentemente sobre as reuniões de transição presidencial. Preparando campo para o governo Carter, os auxiliares de Kissinger sugeriram uma démarche ao governo uruguaio, visando diminuir o impacto das ameaças à Koch caso algum veículo de imprensa divulgasse a história. Siracusa, por sua vez, fez uma retratação sobre seu relatório anterior $e$ garantiu que os uruguaios estavam ativos na Operação Condor e que seria melhor que o Departamento de Estado bloqueasse a entrada de Fons e Gavazzo para evitar problemas futuros. ${ }^{53}$

O caso Koch foi emblemático para que o Departamento de Estado tivesse conhecimento do potencial da Operação Condor. Em dezembro de 1976, o modus operandi das missões de chilenos e uruguaios já era discutido em reuniões do Conselho de Segurança Nacional, que demonstrava preocupação com o poder de infiltração destes agentes. Durante o governo Carter, a pauta de direitos humanos foi vital nas negociações com o Cone Sul, e novas restrições foram impostas por conta dos abusos, especialmente de Argentina e Chile.

Koch deixou o Congresso em 1977 após ser eleito prefeito de Nova York, derrotando o liberal Mario Cuomo. Com a visibilidade conquistada no parlamento, o político adotou a pauta de defesa dos direitos humanos como uma de suas principais bandeiras e destacou que a parceria com a Anistia Internacional para denunciar a ditadura uruguaia era parte de seu legado político. Após a morte de Orlando Letelier e com o plano de assassinato de Koch exposto, a Operação Condor teve um enfraquecimento de seu caráter transnacional a partir da posse de Jimmy Carter. Sem o apoio de jure

\footnotetext{
${ }^{50}$ A agência obteve informações de que, durante um evento social no final de julho de 1976, um oficial militar latinoamericano, supostamente em estado de embriaguez, comentou que os militares estavam extremamente irritados com sua proposta de restringir a assistência militar dos EUA a países latino-americanos por conta das violações de direitos humanos cometidas pelas forças armadas. Este militar também disse que talvez ele "teria que mandar alguém para os EUA para pegar o congressista Koch". A análise inicial da agência desses comentários foi que eles representavam nada mais do que bravatas induzidas pelo álcool. CIA. Letter to Edward Koch. 26 de setembro de 2001.

${ }^{51} \mathrm{Na}$ sua opinião, no caso do Uruguai decidir ir adiante com tal plano, eles confiariam a operação "a apenas uma pessoa, o Major Gavazzo"; e seu modus operandi, disse ele, seria mandá-lo para os Estados Unidos por alguns meses para desenvolver o "plano operacional". Embaixada dos Estados Unidos no Uruguai. Telegram 4652 From the Embassy in Uruguay to the Department of State. 2 de dezembro de 1976.

52 Sem relação e nenhum dos dois terá uma missão Condor. Embaixada dos Estados Unidos no Uruguai. Telegram 4652 From the Embassy in Uruguay to the Department of State. 2 de dezembro de 1976.

${ }^{53}$ Ambos foram impedidos de entrar nos Estados Unidos posteriormente e não iniciaram suas funções em Washington.
} 
da Casa Branca e do Departamento de Estado, as ditaduras do Cone Sul nunca mais consideraram outros ataques nos Estados Unidos e na Europa. A CIA, por sua vez, adotou uma postura independente. Após o Massacre de Halloween de outubro de $1977^{54}$, parte dos agentes ainda ativos no Cone Sul desafiaram Washington ao manter aberto o canal de comunicações com a Operação Condor. No contexto da luta pela redemocratização em vários países da América do Sul e consequente enfraquecimento da Condor per se, durante o governo Reagan todo o know how e a toda estrutura de comunicações patrocinada pela CIA na década de 1970 no Cone Sul foi transferida para a América Central para promover o patrocínio ao Terrorismo de Estado na Operação Charly ${ }^{55}$.

\section{èce}

\footnotetext{
${ }^{54} \mathrm{Na}$ tentativa de reorganizar o aparato de inteligência estadunidense, o então diretor da CIA, Stansfield Turner, promoveu a gradual transição do clássico padrão de inteligência humana (HUMINT) para adotar uma inteligência de sinais (SIGNIT). Dentro da política de direitos humanos do governo Carter, no dia 31 de outubro de 1977, 820 agentes da CIA foram demitidos - mais da metade destes com atuação na América Latina e com comprovado envolvimento nas articulações dos golpes de 1964, no Brasil, e de 1973, no Chile. Outros 147 agentes entraram em um programa de aposentadoria forçada - o que eliminou todos veteranos do Office of Strategic Services, predecessor da CIA. O episódio conhecido na historiografia estadunidense como Halloween Massacre foi uma dura resposta do poder executivo aos abusos da CIA relevados pelo Congresso entre 1975 e 1976, mas enfrentou forte resistência dos agentes de carreira que permaneceram na agência.

${ }^{55}$ Inicialmente financiada pelo governo argentino, a Operação Charly foi criada para replicar a Operação Condor na América Central, visando prisão e morte de líderes comunistas, e foi amplamente patrocinada pela CIA durante o governo Reagan. 


\section{RESUMO}

Este artigo discute a dinâmica da Operação Condor a partir da análise do caso do Congressista estadunidense Edward Koch, responsável pela confecção da emenda parlamentar do Security Assistance Act de 1977 que proibiu a transferência de três milhões de dólares do orçamento do auxílio militar dos Estados Unidos ao Uruguai durante o período no qual as ditaduras do cone sul tinham aval da CIA e do Departamento de Estado para promover o terrorismo de Estado. O plano para o assassinato de Koch, interceptado pelas agências de inteligência dos EUA, mostrou o poder de infiltração da Condor no território estadunidense durante o auge da Operação ao mesmo tempo que comprovou a omissão do poder executivo estadunidense meses antes do assassinato de Orlando Letelier.

Palavras-chave: Edward Koch; Estados Unidos; Operação Condor.
ABSTRACT

This article discusses the dynamics of Operation Condor from the analysis of the case of US Congressman Edward Koch, chief sponsor of the parliamentary amendment of the Security Assistance Act of 1977 which rejected the transfer of three million dollars from the U.S military aid budget to Uruguay during the period in which Southern Cone dictatorships were endorsed by the $\mathrm{CIA}$ and the State Department to promote state terrorism. The plan to murder Koch, intercepted by US intelligence agencies, proves Condor's infiltration power into US territory during the Operation's heyday, as well as show the omission of the US executive power in the same period of the murder of Orlando Letelier.

Keywords: Condor Operation; Edward Koch; United States.

Artigo recebido em 23 jul. 2018.

Artigo aprovado em 15 set. 2018. 
